\title{
СУЩЕСТВУЕТ ЛИ ХРИСТИАНСКИЙ ЭЛЕКТОРАТ В ЕВРОПЕ? ЦЕРКОВЬ, ВЕРУЮЩИЕ И ПОЛИТИКИ
}

\begin{abstract}
Аннотация. В статье проанализирована проблема религиозно мотивированного голосования на европейских выборах, в частности, на выборах в Европарламент. У представителей иерквей нет готового ответа на вызовы общеевропейского кризиса, кроме необходимости следования христианским корням. Тем не менее, и христианство как основа европейской идеи интерпретируется по-разному и христианская демократия как политическая идеология уже далеко ушла от христианства, превратив его скорее в символ. В этой ситуации незыблемой для христианского сообщества оказывается общеевропейская идентичность. Именно во многом благодаря консолидированной позиции иерквей и мнимой или явной угрозе исламизачии единство Евросоюза остаётся и будет оставаться определённой идеологической иенностью. Помимо этого, само по себе понятие идентичности постепенно наполняется содержанием, переходит из лексикона «популистов» в риторику тех, кто непосредственно отвечает за строительство Евросоюза. От внимания к вопросам национального суверенитета и идентичности во многом будет зависеть трансформация европейской идеи и формирование сознания новых европейцев.
\end{abstract}

Ключевые слова: миграция, межрелигиозный диалог, христианство, протестантизм, православие, католицизм, государственно-иерковные отношения.

В ходе предвыборной борьбы за кресла депутатов Европейского парламента (ЕП) ярко проявилась многозначность в восприятии религиозного фактора в политическом контексте. Религия является элементом общеевропейской идентичности в программах части представителей партий «политической альтернативы», которых можно назвать традиционалистами. В глазах церковных лидеров стран Евросоюза (ЕС) христианство тем более является фундаментом общеевропейского единства, а отказ от христианства провозглашается причиной кризиса ЕС. Христианский вопрос и шире вопрос о присутствии религии в обществе и её использовании политиками становится ключом к пониманию различных идеологических разногласий.

Защищая единую Европу от националистов, мигрантофобии, ксенофобии в целом, руководство католических и протестантских церквей в разных странах Евросоюза часто выступает с более либеральных позиций, чем их собственная паства. В предвыборных заявлениях

\footnotetext{
( ) Лункин Роман Николаевич - кандидат философских наук, доктор политических наук, ведущий научный сотрудник, руководитель Центра по изучению проблем религии и общества Отдела социальных и политических исследований Института Европы РАН, заместитель главного редактора журнала «Современная Европа». Адрес: 125009, Россия, Москва, Моховая ул., д. 11, стр. 3. E-mail: romanlunkin@gmail.com.
}

DOI: http://dx.doi.org/10.15211/vestnikieran32019110116 
межцерковных объединений Евросоюза, обращённых к избирателям, содержался призыв пойти и проголосовать на выборах в ЕП, но при этом осознавая «опасность популизма». Фактически те силы, которые открыто говорят о необходимости сохранения национальных традиций и суверенитета, были в той или иной форме осуждены церквями. Можно сказать, что церковное руководство игнорирует мнение консервативно настроенных верующих в своей среде. Таким образом, не только в европейской политике, но и в христианском сегменте общества растёт разделение на либералов (в современном контексте это те, кто исповедует либерализм в смысле примата политкорректности и диктатуры меньшинств) и традиционалистов. Углубление этого раскола хорошо видно по поведению политических деятелей и лидеров церквей (в особенности, показателен пример самой крупной европейской структуры - Католической церкви и межконфессиональных ассоциаций Европы).

В отличие от США в европейской политической и социологической науке намного меньше внимания уделяется тому, как и за кого голосуют верующие. Связано это, во-первых, с предубеждением в отношении роли религии в секулярном обществе, которая якобы ушла в «частную сферу», то есть произошла приватизация религии. Во-вторых, с тем, что число тех, кто себя соотносит с исторической конфессией своего народа (католицизмом, лютеранством, православием), как правило, совпадает с относительным большинством населения, а значит и мало отличимо от того, что думает статистическое большинство. Выявление небольших в процентном соотношении групп убеждённых религиозных активистов считается, скорее, малоперспективным с точки зрения влияния этих групп на общую политическую ситуацию. Действительно, то, как голосуют православные в Греции или католики в Италии в большей степени зависит от того, как политики выстраивают отношения с Евросоюзом и от разрешения социально-экономических проблем.

Ситуация стала меняться с обострением иммиграционного кризиса и с формированием образа «исламской угрозы», связанной как с радикальным исламизмом, так и с преувеличенным представлением о будущей исламизации Европы. Несмотря на видимое присутствие иммигрантов в европейских городах и время от времени случающиеся теракты, возникающие фобии во многом основаны на страхе перед чем-то неизвестным. При этом нельзя недооценивать беспокойство европейцев - оно вполне рационально, так как имеет под собой практическую почву: проблемы с притоком и поведением иммигрантов, радикализация части исламского сообщества и кризис европейской солидарности в ЕС. Как показали выборы в ЕП, этим страхом воспользовались самые разные силы в своих целях: традиционные европейские партии (прежде всего, христианские демократы) обострили у избирателей ощущение необходимости единства Евросоюза перед различными вызовами, «правые популисты» воплотили желание европейцев к изменениям через лозунги о защите суверенитета, идентичности и национальной культуры. В связи с этим стоит заметить, что далеко не только «популисты» играют на народных чувствах, но популистам в данном случае, по сути, являются все политики.

Играет ли какую-то роль христианский электорат в предвыборной борьбе в последние годы и во время выборов в ЕП?

Исследователи отмечают, в частности, большую роль религиозной аффилиации в восприятии евроинтеграции и евроскептицизма на примере референдума в Британии по поводу брекзита (различия есть между католиками и протестантами, а также внутри этих конфессий) ${ }^{1}$. Если к 1990 гг. религиозно мотивированное голосование в Европе почти исчезло (за исключением Восточной Европы), то затем сами политические элиты сыграли большую роль в

\footnotetext{
${ }^{1}$ Kolpinskaya E., Fox S. Praying on Brexit? Unpicking the Effect of Religion on Support for European Union Integration and Membership. JCMS Journal of Common Market Studies. January 2019. P. 1-19. DOI: 10.1111/jcms.12836.
} Научно-аналитический вестник ИЕ РАН, 2019, №3 
активации «религиозного голосования» ${ }^{1}$. Различия между различными христианскими деноминациями в рамках выборов стираются, но более выпуклым становится отличие религиозных избирателей и секуляристов ${ }^{2}$. В случае с Италией авторы подчёркивают традиционно большую личную религиозность итальянских депутатов в Европарламенте (и влияние этого фактора на их голосовании по вопросу о вступлении Турции в ЕС), а также большую роль конфессиональной мотивации во внутринациональных вопросах ${ }^{3}$. Немецкие депутаты в ЕП делают акцент на сотрудничестве государства и религиозных институтов в социальной сфере, более критично относятся к исламу. При этом европейские политики оказываются более религиозными, чем население Германии, но Европарламент более секулярным, чем парламент Германии ${ }^{4}$. Исследования соотношения религии и голосования за различные партии в ЕП показали, что роль религии значительно выросла, и кроме того, христианская мотивация всегда играла роль при голосовании за христианско-демократические и консервативные партии .

Безусловно, не преувеличивая эту роль, следует отметить активизацию граждан, которые идентифицируют себя с той или иной церковью. Особенно ярко это можно увидеть на примерах Франции и Италии.

Об этом говорят исследования, которые проводились в 2010-е гг. К примеру, по данным Института по изучению общественного мнения и маркетинга во Франции и за рубежом (IFOP), в 2015 г. 58\% практикующих католиков положительно оценили призыв папы Франциска ко всем приходам приютить семью мигрантов, 31\% этого не одобрил, $11 \%$ ответили, что равнодушны к этому высказыванию. После личного посещения папой Франциском лагеря беженцев на острове Лесбос отношение к приёму мигрантов значительно выросло в положительную сторону среди католиков. Помимо этого, можно отметить, что в 2015 г. на региональных выборах поддержка Национального фронта и Марин Ле Пен среди практикующих католиков была - 25\%, среди непрактикующих - 34\%, среди людей без религии - 24\%. Часть консервативно настроенных католиков стала поддерживать М. Ле Пен, несмотря на то что сама она провозглашает принцип абсолютной светскости И скорее против усиления роли Церкви в обществе (наряду с этим, в рамках Национального фронта существует группа католиков).

Ещё более заметно группа верующих проявила себя в опросе об исламе. В феврале 2015 г. французы в целом отмечали, что угрозой является не ислам, а радикалы - 62\%, и только - 32\% отметили, что ислам вообще может быть угрозой для страны. В июле 2016 г. настроения французов мало изменились (соответственно, 63\% и 33\%). В том же феврале 2015 г. настроения католиков были идентичны, как и почти всегда ранее, настроениям французов вообще (во Франции по опросам - более $60 \%$ населения называют себя католиками): угрозой является не ислам, а радикалы - $64 \%$, и только - $33 \%$ отметили, что ислам вообще может быть угрозой для страны. Однако в июле 2016 г. мнения католиков разделились: 49\% не считают ислам как таковой угрозой, но 45\% рассматривают ислам как угрозу ${ }^{6}$ Одной из причин изме-

\footnotetext{
${ }^{1}$ Cordero G. Three Decades of Religious Vote in Europe. World Political Science, 13(1), 2017. P. 77-98. Retrieved 6 Jul. 2019, from doi:10.1515/wps-2017-0001.

${ }_{2}^{2}$ Minkenberg Michael. Party politics, religion and elections in Western democracies. Comparative European Politics. December 2010, Volume 8, Issue 4. P. 385-414. URL: https://doi.org/10.1057/cep.2009.5.

${ }^{3}$ Stefano Braghiroli, Giulia Sandri. Religion at the European Parliament: the Italian case, Religion, State and Society, 42:2-3, 227-250, 2014. DOI: 10.1080/09637494.2014.937144.

${ }^{4}$ Anne Jenichen, Henrike Müller. A social role for churches and cultural demarcation: how German MEPs represent religion in the European Parliament, Religion, State and Society, 42:2-3, 148-165, 2014. DOI: 10.1080/09637494.2014. 932081.

5 Dr H.S., van der Brug W., de Vreese C. Religion and Party Choice in Europe. West European Politics, 32(6), 2009. P. 1266-1283.

${ }^{6}$ Le rapport des catholiques à l'islam en France №140. 16.08.2016. URL: https://www.ifop.com/publication/rapportdes-catholiques-a-lislam-en-france/
} 
нения настроений стало зверское убийство 85-летнего священника Жака Амеля 26 июля 2016 г. в храме святого Стефана в городе Сент-Этьен-дю-Рувре, округа Руан, региона Нормандия (Франция) двумя деятелями террористической организации Исламское государство (запрещена на территории РФ).

Конкретно для Франции это означает, что мнения части католиков стали отличаться от мнения большинства французов, а действия католических околоцерковных организаций показывают, что «Католическое действие» или Ассоциация католических семей ещё покажут себя во время гражданских акций. Во Франции также проявился и общий симптом для Европы и для разных регионов мира - религиозный фактор стал политическим мотивирующим.

Политизация религии и верующих происходит, но при этом прямые столкновения представителей церквей и условных «правых популистов» и националистов чрезвычайно редки. Исключением, пожалуй, стала Италия, где Маттео Сальвини подвергся усиленной критике католических прелатов за использование религиозных символов во время предвыборной кампании в ЕП. Несмотря на то что Сальвини отнюдь не является образцовым католиком (он разведён, у него дети от разных женщин), опросы показывают, что за него голосует $33 \%$ практикующих католиков, что делает «Лигу» самой популярной партией среди прихожан ${ }^{1}$. Если в 2018 г. на всеобщих выборах партия Сальвини получила 12\% практикующих католиков, то на выборах в Европарламент в 2019 г. за «Лигу» проголосовало 27\% практикующих католиков $^{2}$. Критике со стороны Ватикана Сальвини подвергся за свою речь в Милане на Соборной площади 18 мая 2019 г. во время политического ралли «Италия прежде всего» с участием других «правых популистов» (его речь слушали Марин Ле Пен и Герт Вилдерс). Тогда Сальвини держал в руках чётки розария и заявил, что посвящает свою жизнь и работу Деве Марии, просит у неё помощи и защиты. Кроме того, по словам Сальвини, «мы вверяем себя в руки шести святых - покровителей Европы: Св. Бенедикта Нурсийского, св. Бригиты Шведской, св. Екатерины Сиенской, свв. Кирилла и Мефодия, св. Терезы Бенедикта Креста ${ }^{3} \ldots$ Мы доверяем нашу судьбу, наше будущее и мир и процветание наших народов им». Лично Сальвини посвятил Италию и свою жизнь Пречистому Сердцу Марии, надеясь, что это принесёт ему победу. Политик упоминал в своей речи папу Иоанна Павла II и папу на покое Бенедикта XVI с их призывом к Европе не забывать о христианских корнях. Дело в том, что Франциск в разной форме критиковал высказывания Сальвини об иммигрантах и открыто заявлял об опасности «популизма». В 2018 г. в Палермо папа Франциск заявил, что единственно приемлемый популизм - это христианский, который не кричит, не обвиняет и не возбуждает ссоры». Понтифика на Сицилии встречала толпа с большим плакатом «Обновим Церковь!», правда, что имели в виду люди, неизвестно ${ }^{4}$. Кроме того, в прессе появлялись сообщения, что Ватикан отказал Сальвини во встрече с папой 5 .

Европейские политики в прошлом часто призывали имена святых и посвящали свои победы Деве Марии, упоминали о наставлениях римских пап. Сальвини считает себя, хоть и не-

\footnotetext{
${ }^{1}$ Ferraresi M. How the Catholic Church Lost Italy to the Far Right. Pope Francis' retreat from culture-war politics has left a void that politicians have been all too eager to fill. The New York Times. July 4, 2019. URL: https://www.nytimes. com/2019/07/04/opinion/catholic-church-italy.html.

${ }^{2}$ Sorgi G. The Pope, the populist and the Italian bishops. 20 JUNE 2019, THE TABLET. URL: https://www.thetablet.co. uk/features/2/16251/the-pope-the-populist-and-the-italian-bishops.

З Этих святых в качестве главных святых покровителей Европы объявили папы Павел VI (в 1964 г. св. Бенедикта Нурсийского) и Иоанн Павел II (в 1985 г. - свв. Кирилла и Мефодия, в 1999 г. - остальных из списка).

${ }^{4}$ Pope says populism should serve people, not stir up quarrels. Associated Press. Crux Catholic Media. Sep 15, 2018. URL: https://cruxnow.com/papal-visit/2018/09/15/pope-says-populism-should-serve-people-not-stir-up-quarrels/

${ }^{5}$ Chapman W.M. Vatican Complaining That Italy's Conservative Interior Minister Invoked Patron Saints \& Virgin Mary. CNSNews.com. 22.05.2019. URL: https://www.cnsnews.com/blog/michael-w-chapman/italys-conservative-interiorminister-publicly-commends-his-work-saints.
}

Научно-аналитический вестник ИЕ РАН, 2019, №3 
достойным и грешным, но католиком. Тем более резкой оказалась реакция на его заявления со стороны Святого Престола. Госсекретарь Ватикана кардинал Пьетро Паролин отметил, что Бог существует для всех, а призывать его только для себя опасно. Сторонник папы Франциска иезуит Антонио Спадаро отреагировал ещё более радикально. По его словам, использование розария в политике неприятно для верующих. Спадаро также сравнил Сальвини с теми евангелистами из США, которые выпустили памятную монету в честь президента Д. Трампа как «точки соприкосновения с Богом». По словам Спадаро, «некоторые используют в избирательных кампаниях Бога и святых, другие продают монеты, чтобы молиться за переизбрание своего кандидата». Один из итальянских епископов даже говорил избирателям, что те, кто голосует за Сальвини - не христиане. Итальянский журнал «Фамилия Кристиана» подчеркнул, что религия эксплуатируется «Лигой», чтобы оправдать нарушения прав иммигрантов в Италии.

Наиболее остроумно отреагировал глава конференции епископов Италии Гуалтьеро Басетти, который заявил, что демонстрация католических символов ещё не делает никого современным Альчидо Де Гаспери (один основателей христианской демократии и Европейского общества). Кроме того, по мнению епископа, разделять католиков и папу неправильно и контрпродуктивно, имея в виду насмешку Сальвини над папой: «А Его Святейшеству Франциску я хочу сказать, что наше правительство спасает беженцев в Средиземноморье с большой гордостью». Вместе с тем разделение уже произошло, так как всё чаще священнослужители говорят о расколе не только среди епископов, но и среди рядового духовенства, которое делится своими симпатиями в отношении «правых популистов» лишь со своими прихожанами. К примеру, священник Альдо Буонайюто (Община папы Иоанна XXIII) призывал к диалогу с такими политиками как Сальвини ради решения важных проблем - защиты жизни, семьи, биоэтики, свободы в образовании и т.д. Именно отец Альдо дал Сальвини розарий, которым он размахивал в Милане ${ }^{1}$.

Ответ Маттео Сальвини своим критикам был кратким: «Я продолжу свидетельствовать о своей вере через мою работу на благо прекрасной и безопасной Италии. Сплетничают пусть другие. Аминь»².

Поскольку идеологические разделения ещё не устоялись, да и позиция лидеров католиков, лютеран часто неоднозначна, позиции партий также совмещают в себе разные элементы для привлечения электората. Где-то больше акцент на национальной самобытности и консервативных католических ценностях, как у партии «Право и справедливость» в Польше. В других случаях акцент делается на сохранении своей идентичности и критике Евросоюза, как в риторике лидера партии ФИДЕС Виктора Орбана (за него выступают католики и Реформатская церковь, к которой он сам принадлежит). В ФРГ партия «Альтернатива для Германии», рассорившись с Католической церковью (которая осудила и идеологию партии и исламофобию, запретив священникам участвовать в движении PEGIDA), безусловно, потеряла часть голосов католиков. Примечательно, что в том, что касается выборов в Европарламент, и выигрыш и проигрыш «правых популистов» связан с активной позицией верующих и Церкви (правда, еврооптимизм и политкорректность лидеров Церкви полностью совпали с настроениями граждан только в Германии, где большинство получил ХДС).

Выборы в Европарламент в 2019 г. стали одной из рубежных дат во взаимоотношениях

\footnotetext{
${ }^{1}$ Sorgi G. The Pope, the populist and the Italian bishops. 20.06.2019, The Tablet. URL: https://www.thetablet.co.uk/ features/2/16251/the-pope-the-populist-and-the-italian-bishops.

${ }^{2}$ Winfield N. Italy's Catholic establishment faults Salvini for rosary. Crux Catholic Media. 20.05.2019. URL: https:// cruxnow.com/church-in-europe/2019/05/20/italys-catholic-establishment-faults-salvini-for-rosary/

Научно-аналитический вестник ИЕ РАН, 2019, №3
} 
европейского истеблишмента и правопопулистских партий. Президент Комиссии епископских конференций Европейского союза архиепископ Люксембургский Жан-Клод Холлерих позитивно отозвался об итогах выборов, отметив, что «люди видят важность европейской политики и чувствуют свою ответственность, приходя на выборы» 1 .

Вместе с тем остаётся больше вопросов, чем ответов, которые связаны как с позицией церковных институтов, так и политических партий, отстаивающих «суверенитет» своих стран в самой разной его интерпретации. Прежде всего, это вопросы о том, как теперь различается и воплощается на практике мнение церковного руководства и простых верующих. И можно ли после скромного результата «правых популистов» на выборах в Европарламент окончательно отвергнуть их призывы и опасения, признав лишь временным всплеском «национализма» и ксенофобии, игрой на чувствах народов Европы. Однако если так произойдёт, то это будет ещё худшей и более циничной игрой на народных настроениях, чем это было у некоторых популистов.

У представителей церквей нет готового ответа на вызовы общеевропейского кризиса, кроме необходимости следования христианским корням. Тем не менее, и христианство как основа европейской идеи интерпретируется по-разному и христианская демократия как политическая идеология уже далеко ушла от христианства, превратив его скорее в символ. В этой ситуации незыблемой для христианского сообщества оказывается общеевропейская идентичность. Именно во многом благодаря консолидированной позиции церквей и мнимой или явной угрозе исламизации единство Евросоюза остаётся и будет оставаться определённой идеологической ценностью. Помимо этого, само по себе понятие идентичности постепенно наполняется содержанием, переходит из лексикона «популистов» в риторику тех, кто непосредственно отвечает за строительство Евросоюза. От внимания к вопросам национального суверенитета и идентичности во многом будет зависеть трансформация европейской идеи и формирование сознания новых европейцев.

\section{Список литературы/References}

Cordero G. Three Decades of Religious Vote in Europe. World Political Science, 13(1), 2017. P. 77-98. Retrieved 6 Jul. 2019, from doi:10.1515/wps-2017-0001.

Braghiroli Stefano \& Giulia Sandri. Religion at the European Parliament: the Italian case, Religion, State and Society, 42:2-3, 227-250, 2014. DOI: 10.1080/09637494.2014.937144.

Brug, Dr, H.S., van der, W., de Vreese C. Religion and Party Choice in Europe. West European Politics, 32(6), 2009. P. 1266-1283.

Jenichen Anne \& Henrike Müller. A social role for churches and cultural demarcation: how German MEPs represent religion in the European Parliament, Religion, State and Society, 42:2-3, 148165, 2014. DOI: 10.1080/09637494.2014.932081.

Kolpinskaya E., Fox S. Praying on Brexit? Unpicking the Effect of Religion on Support for European Union Integration and Membership. JCMS Journal of Common Market Studies January 2019. P. 1-19. DOI: $10.1111 /$ jcms. 12836.

Minkenberg Michael. Party politics, religion and elections in Western democracies. Comparative European Politics. Dec. 2010, Vol. 8, Issue 4. P. 385-414. URL: https://doi.org/10.1057/cep.2009.5.

\footnotetext{
${ }^{1}$ Roberts J. COMECE President finds positives in euro elections. 29.05.2019, The Tablet. URL: https://www.thetablet. co.uk/news/11734/comece-president-finds-positives-in-euro-elections.
} 


\title{
Whether Christian electorate in Europe exists? Church, Believers and Politicians
}

Authors. Roman Lunkin, Candidate of Sciences (Philosophy), Senior Fellow, the Head of the Center for Religious Studies, Institute of Europe, Russian Academy of Sciences, deputy editorin-chief of the journal «Contemporary Europe». Address: 11-3, Mokhovaya str., Moscow, Russia, 125009. E-mail: romanlunkin@gmail.com.

\begin{abstract}
In the article analyzed the problem of the religiously motivated voting on European elections, in particular, on the elections to the European Parliament. The representatives of the Churches don't have the prepared answer on the challenges of the European crisis except the obligatory following to the Christian roots. Therefore the Christianity as the base of the European idea interpreted in different ways and the Christian Democracy went far from the Christianity, converted it into symbol. In that situation the fundamental thing for the Christian communities is European identity. In gratitude to the consolidated position of the Churches and false or true threat of the islamization - the unity of Europe remains the definite ideological value. Besides that the definition of identity itself step by step filling with the content, transferred from the rhetoric of the «populists» to rhetoric of those that are directly responsible for the constructing of the European Union. From the more attention to the questions of the national sovereignty and identity will depend the transformation of the European idea and the creating of the consciousness of the new Europeans.

Keywords: migration, interreligious dialogue, Christianity, Protestantism, Orthodoxy, Catholicism, Church-State relations.
\end{abstract}

DOI: http://dx.doi.org/10.15211/vestnikieran32019110116 